\title{
La involución doctrinal hacia el capital (Centesimus Annus)
}

\author{
Alberto Parra, \\ Asociación de Teólogos Koinonía, \\ Bogotá, Colombia.
}

\section{Introducción}

El "afán de cosas nuevas" (rerum novarum) "que perurban fundamentalmente todo el orden social" fue el objeto de la carta encíclica que hace cien años (15 de mayo de 1881) promulgó el Papa León XIII. Es claro que el sentido que León XIII quiso dar a la expresión rerum novarum era "afán de novelerfas". Como es claro que el "orden social" que resultaba perturbado por las novelerias es el "orden" entre los actores de las fuerzas sociales de producción. "Orden" que era y que es profundo desorden, flagrante injusticia e intolerable realidad.

Sólo que, para bien o para mal, el "orden social" impuesto por la industrialización y por la ideología liberal capitalista encontró en las "novelerías" de hace cien años un elemento científico de crítica y un contrapunto social que no puede serle arrebatado a los pobres, ni siquiera después de la caída de los socialismos históricos.

El valor permanente de las "novelerías" de hace cien años es haber propiciado una forma de acercamiento a la realidad (epistemología), no solo para conocerla teóricamente, sino para transformarla; es haber señalado que el factor económico es un determinante fundamental del proceso histórico; es haber denunciado que, generalmente, la acumulación de capitales es el resultado de la explotación del trabajo de los trabajadores; es haber ofrecido un método de análisis de los fenómenos de la industrialización para desenmascarar las alienaciones econónicas, políticas y sociales que se siguen para los obreros y trabajadores; es haber seftalado que ciertas formas de religión y de "evangelización" no son sino opio y dormidera de la conciencia del trabajador para que se resigne y deje las manos libres a los avivados de la libre empresa; es haber propuesto una utopia para avanzar hacia una sociedad sin clases y sin hirientes 
desigualdades. El fracaso histórico de los socialismos reales en la Europa del este no resta un ápice a eslos valores permanentes de las "novelerías" que continuarán siendo una contrapartida a la ideología capitalista, una fuerza de desenmascaramiento y un motor para la reivindicación de los derechos conculcados de los pobres, de los obreros, de los empleados, de las clases empobrecidas y subordinadas.

A su vez, las "cosas nuevas" dc hoy son, fundamentalmente, la caída o el fracaso de los socialismos reales que pretendieron ser dogmáticamente la sola y la única posibilidad de alternativa frente al capilalismo y que terminaron en la más aberrante intolerancia, en la identificación de las grandes tesis del socialismo con un partido anacrónico y no revisionista, en el totalitarismo de Estado, en la negación rotunda de toda forma de propiedad privada, en la práclica desaparición de los derechos individuales de opinión, de expresión, de asociación, de religión, de procreación, de transmigración, en fin, en el imperialismo expansionista que quiso imponer, por la razón o por la fuerza, el propio modelo a otros conglomerados y acabó siendo cl exportador de revoluciones a los países ccrcanos y a los lejanos.

Ante el fracaso de los socialismos reales, la otra gran "cosa nueva" es la pretensión del capitalismo de erigir la economía de mercado y la ideología sustentadora como la única altemativa viable y de resultados benéficos históricamente comprobables.

De ahí que, a los cien años de las "novelerías" de ayer y al comienzo mismo de las "cosas nuevas" de hoy, el papa Juan Pablo II proclame ahora su nueva encíclica (Centesimus Annus) cuyo plan es, precisamente, una mirada retrospectiva al texto de León XIII para descubrir la riqueza de los principios formulados, y una mirada a las "cosas nucvas" que hoy nos rodean.

No queremos volver aquí sobre la riqueza de los "principios formulados" por León XIII y reactualizados en todo cl cucrpo de doctrina o enseñanza social de la Iglesia a lo largo de estos cien años. Basta con reiterar aquí la comprobada impresión latinoamericana de que los "principios formulados", válidos y verdaderos, enriquecen la doctrina y alimentan el saber, son progresistas en la formulación e incluso arriesgados en la expresión. Pero, como loda teoría sin praxis y sin mediaciones, esos "principios formulados" son liberadores del pensamiento, pero no de la miseria de la realidad. Ofrecen tesis avanzadas sobre la realidad, pero no la modifican. No son inspiradores de modelos alternativos. No se deciden por instrumentales alternativos para el análisis de la realidad. No apuntan a opciones políticas disyuntivas. No acompañan las consecuencias útimas en las que los principios formulados se verifican en la planificación de metas y de estrategias de cambio y de alternativa social.

Aquí preferimos fijamos en las "cosas nuevas" que hoy nos rodean y que, 
como el mismo papa Juan Pablo II lo indica, son fudamentales para los "países del tercer mundo, que buscan la vía del verdadero progreso económico y civil" (n. 42).

El plan que proponemos es el de fijamos, primero, en los puntos luminosos de la enciclica Centesimus Annus y en su repercusión e importancia para la causa de los pobres. Y luego subrayar los puntos que parecen sombrios para esa misma causa.

\section{Luces y esperanzas}

El Papa formula un elemento fundamental en la concepción modema de la historia y de la sociedad: el inevitable conflicto de intereses entre los diversos actores o grupos sociales. Ya otros documentos eclesiásticos se habían referido a la "lucha de clases" para enterderla como "conflicto social agudo", en el cual el cristiano se ve necesariamente impelido a tomar partido por los intereses de los débiles, configurándose así la lucha por la justicia social (n. 14).

Esta inevitabilidad del conflicto social (si es que se quiere al fin superar esa versión caricaturesca de la lucha de clases como odio y destrucción del adversario) conduce, entonces, a que los actores del conflicto de intereses busquen soluciones concertadas y transacciones políticas. "Porque la paz no puede ser el resultado de la victoria militar, sino la superación de las causas de la guerra" (n. 18). Y causas reales de la guerra y del conflicto son, según el Papa, las injusticias sufridas, las frustraciones, la miseria y la explotación (n. 52). En ese contexto, el papa Juan Pablo II reconoce aquello que ha sido una honda experiencia latinoamericana: que en el enfrentamiento sistemático que se dio entre los bloques oriental y occidental, esos adversarios implacables utilizaron a los pobres para crearse recíprocos obstáculos. Fue cuando los procesos de liberación se tildaron y se persiguieron sistemáticamente como penetración del comunismo, scgún los casos históricos de Nicaragua y El Salvador, de Colombia y de Vietnam.

En el cnfrentamiento actual del bloque norte contra el bloque sur, las decisiones políticas y sociales de los pobres están hipotecadas a los préstamos internacionales y a las políticas que trazan los ricos para los pobres (n. 18).

La caída de los socialismos reales (confundida en la encíclica como la "crisis del marxismo") no significa que se hayan superado ya las situaciones de injusticia y de opresión que el marxismo denunciara. Por eso hoy, tanto o más que ayer, tiene plena vigencia y plena actualidad la genuina praxis y teoria de la liberación (n. 26). La doctrina social de la Iglesia, cuyo valor para la liberación es reiterado por la encíclica, conserva, evidentemente, todo su significado de símbolo de la conciencia eclesial acerca de la justicia social, aunque, como es obvio, esa "doctrina" haya de ser continuamente concretizada en la praxis y por 
las mediaciones sociales, por las tesis políticas, por la organización popular, por la planificación, por la lucha de cada día en el camino de los pobres.

En idéntico sentido afirma el Papa que ni la carda de los socialismos ni la relativa humanización del capitalismo significan que se hayan superado ya las profundas carencias que en sí mismo presenta el sistema capitalista (n. 33).

De allf se sigue una afimación vertebral de toda la encíclica: "Queda mostrado qué inaceptable es la afirmación de que la derrota del socialismo deje al capitalismo como único modelo de organización econórnican (n. 35). Porque el riesgo del momento es ceder a la pretensión ideológica capitalista de que los fenómenos de marginalidad, de alienación y de explotación del tercer mundo, ni siquiera se deben plantear, porque el sólo afrontarlos está ya desacreditado de antemano, tras el fracaso de los modelos socialistas (n. 42).

En esta lógica, ciertamente luminosa de la encíclica, el Papa reitera la conocida postura cristiana ante la deuda externa de los paises pobres. Pagar las deudas es un axioma ético. Exigir su pago por encima de las necesidades vitales y básicas del deudor es ilf́cito, no es ético, es inmoral (n. 35).

Lógica consecuencia de lo anterior es que "el amor por el hombre y sobre todo por el pobre se concreta en la promoción de la justicia" (n. 58). Amor que es más créble por las obras, antes que por el razonamiento de la lógica doctrinal (n. 57) y que deberá afrontarse con iniciativa y con riesgo "en el cambio de estilos de vida, de los modelos de producción y de consumo, de las estructuras de poder que rigen hoy la sociedad" (n. 58).

\section{Oscuros nubarrones}

Las páginas luminosas que alientan la causa de los pobres se ven neturalizadas y opacadas por oscuros nubarrones en el cielo de la doctrina social de la Iglesia, propuesta por esta encíclica.

Primer nubarrón en el sombrío panorama es la nivelación que se establece entre el derecho de propiedad privada de los medios de subsistencia digna, el derecho de propiedad de la tierra por quien la trabaja, y la propiedad privada de los medios de producción. Estos tres elementos diferentes del derecho de propiedad no han tenido ni podrán tener jamás un tratamiento único, ni una nivelación, ni una legitimación homogénea. Nivelar esas tres formas de propiedad privada lleva al Papa a baldonar las formas de propiedad colectiva de los medios de producción, y a pensar que el atraso y el subdesarrollo están ligados, precisamente, a la ausencia del sistema de propiedad privada de los medios de producción. La conclusión que se impone es que la pobreza del tercer mundo se explica por la ausencia o no suficiente incidencia del sistema capitalista y que, cuanto más se implemente este sistema, tanto más mejorará su suerte (n. 6). 
El segundo nubarrón ya se venia formando desde tiempo atras, la opción por el pobre, según esta encíclica y otra anterior, "es defínida como una forma especial de primacía en el ejercicio de la caridad cristiana" (n. 11). La opción por el pobre, que es un concepto fundamental en la Iglesia, ha venido sufriendo. como tantas cosas importantes, un alarmante proceso de involución. En Medellín, y en la elaboración teológica subsiguiente, la opción por los pobres fue vista como exigencia fundamental de la fe y derivado teológico inseparable de la revelación de Dios. Pero ya en Puebla esa opción recibe el adjetivo atenuante de "preferencial" y all' mismo se intenta nivelar la opción exigitiva por el pobre con la opción simplemente pastoral por los jóvenes. En los documentos papales que autocita, Juan Pablo II concibe semejante opción exigitiva de la fe y de la revelación como una simple forma genérica de la caridad, con el consiguiente debilitamiento de la opción misma y de todo aquello que la opción por los pobres presupone y exige: la opción por los intereses de los pobres, la opción por su clase social, la opción por las mediaciones sociales altemativas, la opción por los instrumentales políticos y económicos que conduzcan a la real liberación del pobres e impidan que la opción por el pobre se convierta en un puro sentimentalismo o compromiso verbal.

Con las premisas anteriores, la encíclica expresa sin rodeos su complacencia cierta y su bendición inequívoca al libre mercado (n. 34), a la apertura del mercado internacional (n. 33), al nuevo capitalismo (n. 40), a la libre empresa, a la propiedad privada de los medios de producción, a la lógica de la competencia (n. 42). Todo ello no se compagina con la rotunda afirmación de que el fracaso de los socialismos reales no puede hacer pensar que la sola y la única altemativa sea el sistema capitalista con todo el aparato ideológico que lo sustenta. Aquí se tiene la impresión de que Polonia y detrás la Iglesia entera regresan a los brazos amorosos del capitalismo internacional y que nada menos que el Papa se convierte en el gran teólogo del neocapitalismo y de la nueva derecha. Por eso la invitación conclusiva que se formula en la enciclica es para volver a pensar, como en los años 60, que "el otro nombre de la paz es el desarrollo" (n. 52) y no, precisamente, la liberación de los oprimidos por un sistema desarrollista injusto.

En fin, nubarrones oscuros en el cielo de la doctrina social son esas afirmaciones esparcidas que respaldan el triunfo histórico del capitalismo: "Da la impresión de que el libre mercado sea el instrumento más eficaz para colocar los recursos y responder eficazmente a las necesidades" (n. 34). "En las precedentes fases de desarrollo, el hombre ha vivido condicionado bajo el peso de la necesidad... Hoy el problema es la demanda de calidad" (n. 36). "Ciertamente los mecanismos de mercado ofrecen ventajas seguras: ayudan a utilizar los recursos, favorecen el intercambio" y aseguran la competencia (n. 40). Tanto más, cuanto que "en la sociedad occidental se ha superado la explotación, al menos en las formas analizadas y descritas por Marx" (n. 41). Afírmación ésta que no sólo 
sorprende, sino que hiere la conciencia de tres cuartas partes de la humanidad, con sus millones de muertos por hambre, desnutricion, hacinamiento, desempleo, subempleo y salarios de hambre.

Lo sombrío de este cuadro se intensifica aún más, cuando la misma encíclica resume así todo el núcleo de las "novedades" de hoy: "Volviendo ahora a la pregunıa inicial, ¿se puede decir quizás que, después del fracaso del comunismo, el sistema vencedor sea el capitalismo y que hacia él estén dirigidos los esfuerzos de los países que tratan de reconstruir su economia y su sociedad? ¿Es quizás éste el modelo que es necesario proponer a los paises del tercer mundo, que buscan la ví del verdadero progreso económico y civil? La respuesta obviamente es compleja. Si por "capilalismo" se entiende un sisterna económico que reconoce el papel fundamental y positivo de la empresa, del mercado, de la propiedad privada y de la consiguiente responsabilidad para con los medios de producción, de la libre creatividad humana en el sector de la economía, la respuesta ciertamente es positiva, aunque quizá sería más apropiado hablar de "economía de empresa", "economía de mercado", o simplemente de "economía libre" (n. 42).

Queda, pues, la impresión de que el sol de la liberación y de la esperanza de los pobres en la doctrina social de la Iglesia se ha ocultado detrás de los negros nubarrones y que hoy son más lo elementos de ansiedad y de perplejidad que los de confurmación en las exigencias sociales de la fe. 